\title{
La cohesión de la élite y el poder oligárquico*
}

\section{Elite cohesion and the endurance of the Peruvian oligarchy}

\author{
DENNIS GILBERT \\ Hamilton College \\ dnngilbert@aol.com
}

\section{RESUMEN}

El poder oligárquico en Perú duró más tiempo que en cualquiera de los mayores paises de América Latina. Una oligarquía de familias acaudaladas influyó en la política peruana prácticamente en forma continua desde 1895 hasta 1968. Aun cuando no lograron dominar, los oligarcas ejercieron un fuerte poder de veto. Este trabajo examina la perdurabilidad de este poder oligárquico desde la perspectiva de la teoría clásica sobre élites. En particular, enfoca en el problema de la cohesión de las élites, en la forma en que fue puesta a prueba en la abortada elección de 1936.

Palabras clave: oligarquía, élites, elección de 1936, poder politico, APRA.

\section{ABSTRACT}

Oligarchic power endured longer in Peru than in any other major Latin American nation. An oligarchy of wealthy families swayed Peruvian politics almost continuously from 1895 to 1968. Even when they did not dominate, the oligarchs exercised a powerful veto. This paper examines the resilience of oligarchic power through the lens of classical elite theory. In particular, it focuses on the problem of elite cohesion as it was tested in the aborted 1936 election.

Keywords: Oligarchy, Elites, 1936 election, Political power, APRA.

*Traducción de Liliana Samamé. 
Gl poder de la oligarquía perduró en el Perú por más tiempo que en Cotros de los grandes países de América Latina. ${ }^{1}$ Con la notable excepción de los años veinte, una oligarquía de familias adineradas dominó casi en forma continua desde 1895 hasta el año 1968. Aun cuando no dominaban, los oligarcas ejercían un veto poderoso. Mi intención aquí es examinar la resistencia del poder de la oligarquía a través del lente de la teoría de la élite clásica. En especial, quiero enfocarme en el problema de la cohesión de la élite como se probó en la abortada elección de 1936.

El poder de la oligarquía no fue ilimitado, ni tenía por qué serlo. Los oligarcas generalmente obtuvieron lo que necesitaban del Estado: el mantenimiento de políticas económicas laissez faire orientadas a la exportación, la contención de movimientos políticos amenazadores y, especialmente, el control sobre la mano de obra barata de la que dependían. Había otras élites peruanas con cierta pretensión a la fortuna y al poder: los terratenientes de la sierra o gamonales; algunos industriales, a menudo inmigrantes, independientes de la oligarquía; los grupos de la ganadería y el comercio del sur; y, por supuesto, el cuerpo de oficiales militares. Pero la riqueza de los oligarcas era mucho más grande y diversa que cualquiera de estos. Su poder político era local (en las regiones donde se ubicaban sus empresas de exportación) y también nacional. Combinaban la fortuna y el poder con el enorme prestigio social. Las fuerzas armadas, una amenaza potencial para el poder oligárquico fue, al menos hasta la década de los sesenta, uno de los principales apoyos del antiguo régimen. Incluso los dos presidentes militares de larga data y

1 He desarrollado este razonamiento contrastando con otros países de América Latina en Gilbert 2017. Partes de este artículo se basan en las entrevistas realizadas en Lima durante los ańos 1973 a 1975 . Debido a que usualmente estas entrevistas tratan sobre gente poderosa y asuntos sensibles, prometía mantener la confidencialidad a la mayoría de las personas entrevistadas. Rápidamente, aprendí que esta garantía era lo más importante para los miembros de los clanes oligárquicos que aceptaron conversar conmigo sobre sus propias familias.

He citado ampliamente la correspondencia de los Aspíllaga, que consulté en Lima en 1974, en lo que entonces se llamó el Centro de Documentación Agraria. A menos que se indique lo contrario, todas las cartas citadas fueron intercambiadas entre miembros de la familia. 
relativamente independientes, los generales Oscar Benavides y Manuel A. Odría, protegieron los intereses de la oligarquía al resistir las amenazas sociales desde abajo y aplazando a los oligarcas en la política económica. ${ }^{2}$

\section{AMENAZAS Al PODER DE LA Élite: DESDE ADENTRO Y POR DEBAJO}

Según el teórico de la élite Vilfredo Pareto, «Siempre es una oligarquía la que gobierna». Su contemporáneo, Gaetano Mosca, dio una explicación simple: «Una minoría organizada» inevitablemente domina a «una mayoría no organizada». "Cien hombres actuando de manera uniforme y de común acuerdo con un entendimiento común, triunfarán sobre mil hombres que no están de acuerdo y, por lo tanto, pueden ser tratados uno por uno». ${ }^{3}$ La teoría de la élite es vulnerable a dos líneas principales de crítica. ${ }^{4}$ Están, en efecto, dirigidos a la minoría organizada de Mosca y a su mayoría no organizada. El primero se refiere al problema de la cohesión de la élite: ¿Pueden las élites, que a menudo están divididas por intereses y ambiciones en conflicto, mantener su dominio durante mucho tiempo? La segunda es una objeción marxista: ¿Puede el poder de la élite sostenerse frente a una resistencia creciente, organizada y popular? Pareto y Mosca solo tuvieron que mirar a su alrededor para ver el desafío a los gobernantes de la Europa de principios del siglo XX, planteado por el surgimiento de una clase obrera moderna y las organizaciones laborales y políticas que defendían sus intereses. El desarrollo capitalista pronto produciría un reto similar en los gobernantes del Perú. Ante la resistencia popular, la solidaridad de la élite sería crítica para la supervivencia del poder oligárquico.

\section{¿QUIÉNES ERAN LOS OLIGARCAS?}

Para responder a las preguntas planteadas anteriormente con respecto a la oligarquía peruana, necesitamos saber de quiénes estamos hablando. ¿Quiénes eran los oligarcas? Para los propósitos de este documento, eran

2 Cotler 1978; Favre 1969; Bourricaud 1969a; Burga y Flores Galindo 1984: 84-88;

Miller 1982; Gonzales 1985 y Gilbert 2017: 97-146.

3 Pareto 1935: 1426, 1439; Mosca 1939: 50.

4 Bottomore 1966. 
los miembros de las 29 familias nombradas en el cuadro 1 . Me referiré a ellos como los «29 Oligarcas» o simplemente como los «29». La lista se basa en la opinión de siete expertos peruanos, que fueron entrevistados por separado a mediados de los años setenta. Entre ellos, se encontraban miembros de dos de las familias incluidas en la lista, un abogado con muchos clientes de clase alta, dos periodistas muy reconocidos y uno de los principales líderes del partido APRA (Alianza Popular Revolucionaria Americana). Se les pidió a todos que nombraran a las familias que comprendían "la oligarquía» (un término de uso común en el Perú del siglo XX), limitándose a aquellos que habían sido importantes en algún momento entre los años 1930 y 1968. La recopilación de una lista de este tipo conlleva riesgos inevitables: inclusiones y exclusiones cuestionables. Pero, dada la experiencia y los diversos puntos de vista de los jueces, creo que proporciona una base bastante razonable para el análisis. ${ }^{5}$

Generalmente, los 29 Oligarcas poseían fortunas acumuladas de la exportación, minería, finanzas y comercio durante finales del siglo XIX. Para el año 1900, la mayoría estaba representada en el exclusivo Club Nacional de Lima, un logro que significaba tanto la riqueza como el grado de aceptación por parte de la sociedad de élite. Las familias se enumeran aquí sobre la base principal de su fortuna, aunque la mayor parte de las fortunas oligárquicas se diversificaron en varios sectores económicos. Una familia con plantaciones podría invertir en la minería también. Los hacendados y los comerciantes a menudo invirtieron en la banca. ${ }^{6}$

Esta lista de familias oligarcas se superpone notablemente con otros esfuerzos por delinear a la élite nacional. Por ejemplo, Portocarrero Suárez analizó los estados de los difuntos ricos, utilizando registros oficiales del período de 1916 a 1960. Entre los 100 más ricos de los difuntos, 24 individuos (incluyendo 7 de los 10 primeros), eran miembros de los 29 Oligarcas. Veinticuatro de los 29 estaban representados en la muestra total de los 800 difuntos ricos de la lista de Portocarrero. ${ }^{7}$

5 Para una descripción más detallada del método utilizado para seleccionar estas familias, ver Gilbert 2017: 267-268.

6 Favre 1969; Portocarrero Suárez 2013: 78-87.

7 Las cinco familias no representadas eran Banchero, Berckemeyer, Málaga, Mujica, y Picasso. La fortuna Banchero estaba aún formándose en los años cincuenta y su fundador, 
Cuadro 1. Familias de la oligarquía por sector y ańo de ingreso al Club Nacional

\begin{tabular}{|c|c|c|c|}
\hline $\begin{array}{l}\text { SECTORES DE } \\
\text { EXPORTACIÓN }\end{array}$ & $\begin{array}{l}\text { Año de ingreso al } \\
\text { Club Nacional }\end{array}$ & $\begin{array}{l}\text { SECTORES } \\
\text { URBANOS }\end{array}$ & $\begin{array}{l}\text { Año de ingreso al } \\
\text { Club Nacional }\end{array}$ \\
\hline Hacendados & & Banqueros & \\
\hline Aspíllaga & 1886 & Ayulo & 1883 \\
\hline Barreda & 1869 & Lavalle & 1892 \\
\hline Beltrán & 1872 & Prado & 1890 \\
\hline Carrillo de Albornoz & 1903 & & \\
\hline Chopitea & 1894 & \multicolumn{2}{|c|}{ Comercio, industria, otros urbanos } \\
\hline Gildemeister & 1859 & Brescia & 1954 \\
\hline Graña & 1897 & Berckemeyer & 1888 \\
\hline Larco & 1900 & Ferrand & \\
\hline Mujica & 1875 & Miró Quesada (diario) & 1875 \\
\hline Olaechea & 1895 & Wiese & 1917 \\
\hline Orbegoso & 1890 & & \\
\hline Pardo & 1881 & \multicolumn{2}{|l|}{ OTROS, DIVERSOS } \\
\hline Piedra, de la & 1918 & Benavides & 1912 \\
\hline Picasso & 1895 & & \\
\hline Ramos & 1907 & & \\
\hline Mineros & & & \\
\hline Bentín & 1895 & & \\
\hline Fernandini & 1912 & & \\
\hline Málaga & 1907 & & \\
\hline Rizo Patrón & 1926 & & \\
\hline $\begin{array}{l}\text { Exportador de harina a } \\
\text { Banchero }\end{array}$ & de pescado & & \\
\hline
\end{tabular}

Fuentes: Lasartes Ferreyros 1938; Quiróz 1984; Basadre 1968 y 1971; Bertram 1974a y 1974b; Thorp y Bertram 1978; Klarén 1976; Malpica 1973; Pacheco 1923; Belmont 1919; Paz Soldán 1921; Bollinger 1971; Mendiburu 1874-1890; Moreno Mendiguren 1956. Ver también Gilbert 2017: 11-13. Además se han consultado las Memorias del Club Nacional.

Luis Banchero, era relativamente joven. Las otras, todas familias prominentes del siglo veinte, pudieron haber sido excluidos por azar de la muestra sacada por Portocarrero $S$. de los 30,000 casos inviduales. Su método no es claramente definido. 
Quiroz describió a los grupos de inversionistas prominentes durante el período de 1884 a 1930 , es decir, la era anterior a las décadas para las cuales se definieron los 29 Oligarcas. ${ }^{8}$ Entre ellos, se encontraban once grupos de la costa, todos basados en la familia, cuyas inversiones fueron las más diversificadas y significativas para la economía nacional. Siete de los once eran miembros de los 29 Oligarcas: Aspíllaga, Ayulo, Carrillo, Larco, Miró Quesada, Pardo y Prado. Por supuesto, los grupos de inversionistas de Quiroz y los 29 Oligarcas, como todas esas listas, son inevitablemente retratos de duración limitada. Rory Miller, al escribir sobre la República Aristocrática (1895 a 1919), advirtió contra la fácil suposición de la continuidad de la élite durante largos períodos. ${ }^{9}$ En el mejor de los casos, las fortunas familiares tendían a disiparse de generación en generación. Pero dadas las tensiones económicas y políticas impuestas por la Gran Depresión, la supervivencia en la cúspide de siete de los once de Quiroz es notable (la familia del presidente Augusto Leguía estuvo entre las cuatro «no sobrevivientes»).

\section{LAS BASES DE LA COHESIÓN DE LA ÉLITE}

La información en el cuadro 1 sugiere las bases económicas y sociales para la cohesión de la élite. La gran mayoría de los oligarcas peruanos eran hacendados y mineros, cuyas fortunas dependían del mantenimiento de una economía política amigable con las exportaciones y una fuerza laboral numerosa, disciplinada y de salarios bajos. En defensa de sus intereses comunes, se juntaron formalmente a través de organizaciones como la Sociedad Nacional Agraria y los periódicos que poseían; e informalmente (a veces de manera conspiradora), por ejemplo, financiando silenciosamente las campańas políticas y los golpes militares contra gobiernos hostiles. Incluso, las familias no exportadoras de la oligarquía tenían un interés común en la salud económica de sus pares exportadores, ya que toda la economía peruana de este período dependía en gran medida de las exportaciones agrícolas y de minerales.

8 Quiroz 1984.

9 Miller 1982. 
El Club Nacional, en el que todas, excepto una de las familias de la oligarquía, estaban representadas, fue un lugar clave en el mundo social íntimo y de la clase alta que habitaban. ${ }^{10}$ Este club estaba compuesto de varios cientos de familias limeñas. En la cumbre de dicha sociedad de la clase alta, estaba una élite de unas ochenta y ocho familias, cuyos miembros eran, según cuatro observadores expertos, las personas que tenían más probabilidades de ser invitadas a las reuniones sociales exclusivas; cuyas invitaciones eran las más valoradas; y cuyos hijos eran considerados como los más prestigiosos prospectos matrimoniales. ${ }^{11}$ Veinte de los veintinueve clanes oligárquicos se contaron entre estas ochenta y ocho familias de la sociedad de élite. Al menos seis de los nueve que no estaban incluidos estaban vinculados por matrimonio a familias de los ochenta y ocho.

La vida social de los oligarcas se concentró en Lima, a pesar de que las plantaciones y minas de la mayoría estaban lejos de la capital. ${ }^{12}$ Vivían en vecindarios relativamente pequeños, primero en el tradicional centro colonial de la ciudad, pero, con una mayor dependencia del automóvil en la década de 1920, se trasladaron a áreas al oeste, por la nueva avenida Larco. Los limeńos de clase alta se conocían desde la infancia como vecinos y compañeros de aula en escuelas privadas de la élite; especialmente, La Recoleta para niños y el San Pedro para las nińas. Muchos pasaban las vacaciones de verano en el balneario de Ancón. A lo largo de

${ }^{10}$ La excepción fue la familia del magnate de la harina de pescado, Luis Banchero, quien acumuló una considerable fortuna durante los años cincuenta y sesenta, pero que nunca fue aceptado en el Club Nacional. Banchero no es una figura relevante con nuestro tema aquí, ya que en la época de las elecciones de 1936 tenía sólo nueve años. Ver Thorndike 1973.

${ }^{11}$ Los 88 fueron seleccionados por cuatro entrevistados a mediados de los setenta: dos miembros de familias socialmente importantes, una directora de la página social en una de los principales periodicos del país y otro observador cercano de la sociedad de clase alta. Se les pidió que nombraran a las familias que mejor encajaran en este perfil durante el período comprendido entre los ańos 1930 a 1960. Cada familia incluida en el grupo de los 88 fue nombrada al menos por tres de los entrevistados.

${ }^{12}$ Por el contrario, en Brasil o México durante los años de poder de la oligarquía, la vida de la élite fue regionalmente descentralizada y la cohesión fue relativamente débil a nivel nacional. 
sus vidas, estuvieron rodeados de personas como ellos, que eran sus familiares, sus amigos y, generalmente, los hijos de los amigos de sus padres. Las personas con las que socializaban como adultos se encontraban en el Club Nacional, invirtieron e hicieron política con ellos. De tal modo, probablemente fueron personas que se conocieron durante muchos años.

Inevitablemente, se casaban entre ellos. La clave al poder cohesivo de la sociedad de clase alta era la densa red de parentesco creada por décadas de endogamia de la élite que se revela en las detalladas genealogías familiares. ${ }^{13}$ A mediados del siglo veinte, tres cuartas partes de los clanes oligárquicos mencionados en el cuadro 1 se relacionaron con al menos dos de los otros. El sesenta y nueve por ciento de ellos tenían vínculos matrimoniales contemporáneos con al menos una de las ochenta y ocho familias de la sociedad.

Los oligarcas peruanos estaban, como se verá, a veces divididos por intereses en conflicto, ambiciones personales y preocupaciones idiosincráticas de las familias individuales. La sociedad de la clase alta proporcionó una fuerza compensatoria a tales amenazas a la cohesión de la élite. Como lo ha demostrado la investigación en ciencias sociales, las personas en general, y las élites en particular, son más sensibles a los sentimientos y están abiertas a las opiniones de quienes se encuentran como miembros de los grupos socialmente cohesionados. ${ }^{14}$ Además, los lazos sociales de los oligarcas crearon un poderoso mecanismo de control social que se extendió a los negocios y a la política. En su mundo íntimo, el costo social de ofender a sus amigos, parientes, compańeros del club y, por extensión, a personas importantes para ellos, podría ser considerable. La experiencia de los Miró Quesada, dueños de El Comercio, el periódico más influyente de Lima, ofrece un ejemplo revelador. A fines de los

${ }^{13}$ Cada una de las genealogías siguió a los descendientes de un ancestro fundadorusualmente un hacendado, minero, o empresario urbano de finales del siglo XIX - hasta mediados del siglo XX. La fuente principal de los datos genealógicos eran las ediciones sucesivas del registro social limeño, El Libro de Oro, complementado con entrevistas. He realizado las consultas al genealogista Luis Lasarte Ferreyros y a su libro Familias Establecidas.

${ }^{14}$ Baltzell 1958: 61; Domhoff 1974: 36.6. 
años cincuenta y sesenta, El Comercio abandonó el consenso político conservador de la elite y comenzó a pedir algunas reformas sociales y económicas modestas. En respuesta, los Miró Quesada fueron sometidos a presiones económicas por parte de los anunciantes y las autoridades fiscales. También pagaron un precio social. En el Club Nacional, fueron tratados con frialdad por algunos miembros. En sus escuelas privadas, los niños Miró Quesada soportaron las burlas de sus compañeros de clase que los llamaban «comunistas». El hecho de que pudieran resistir tales presiones es un tributo al orgullo familiar y a su posición de larga data en la cúspide de la sociedad de clase alta (se contaban entre las ochenta y ocho y tenían numerosos lazos de parentesco con otras familias oligárquicas y de la élite social). Pero su trato fue una señal fuerte para otros, tal vez de una posición social menos segura, del costo de la independencia.

\section{DE LA REPÚBLICA ARISTOCRÁTICA A LA REPÚBLICA CUESTIONADA}

Podemos pensar que los años de poder de la oligarquía en el Perú se dividen en tres períodos: la República Aristocrática (1895 a 1919), el Oncenio (1919 a 1930) y lo que llamaré la República Cuestionada (1930 a 1968). Durante el período conocido por los historiadores como la República Aristocrática, el país era una democracia patricia, gobernada abierta y directamente por la élite que dominaba la economía peruana orientada a la exportación. Su vehículo político, el Partido Civilista era, según Carlos Miró Quesada, el hijo de una de sus figuras más conocidas, el partido de "grandes terratenientes, banqueros, comerciantes, jefes rurales, rentistas y abogados». ${ }^{15}$ Los presidentes, en un régimen que favorecía el poder presidencial, solían ser los dueños de las plantaciones de azúcar o los miembros de familias azucareras. Tal fue el caso de los presidentes Eduardo López de Romaña, José Pardo y Augusto B. Leguía. Ministros clave de los gabinetes fueron elegidos de grupos similares. El Congreso incluyó miembros de clanes oligárquicos, pero también hombres que representaban a la élite terrateniente serrana, quienes poseían menos riqueza que los hacendados costeños.

${ }^{15}$ Miró Quesada Laos 1961: 356. 
Frente a una resistencia limitada desde abajo, los caballeros de la República Aristocrática tenían la libertad de enfrentarse entre sí. Ya en el año 1904, los civilistas se habían dividido en líneas generacionales, en gran parte por cuestiones laborales, pero fue la ambición personal de un hombre, Augusto B. Leguía, lo que finalmente destruyó al Partido Civilista y a la República Aristocrática. Leguía se había elevado de sus orígenes provincianos de clase media a la élite nacional gracias a su talento, encanto y a un matrimonio ventajoso. El perfil de su fortuna en las finanzas y las plantaciones agrícolas era típico de la élite. Fue admitido en el Club Nacional antes de los 30 años. En 1908, a la edad de 45 años, Leguía fue elegido presidente del Perú por el Partido Civilista, pero rápidamente alienó a un gran sector del partido por su estilo personalista y autoengrandecido. Leguía, quien se separó de los hombres que una vez fueron sus compañeros en el Club Nacional, buscó un segundo mandato presidencial en 1919. Ahora se presentaba como el antioligarca y cortejó a los estudiantes, así como a los trabajadores urbanos y los votantes de clase media. Tras su victoria sobre el hacendado Antero Aspíllaga, un candidato civilista tradicional, Leguía tomó el poder a través de un golpe militar contra el gobierno oligárquico saliente de José Pardo. Leguía afirmó que sus enemigos estaban conspirando para anular su victoria. Cualquiera que sea su motivación, el golpe de Estado le permitió disolver el Congreso y crear un nuevo régimen que podría dominar.

El golpe de estado de 1919 inauguró el Oncenio, la dictadura de once años de Leguía. Al asumir el cargo, Leguía anunció sus intenciones: «He venido a liquidar el viejo estado de cosas, pero también a detener el avance del Comunismo». ${ }^{16}$ Leguía expulsó a los oligarcas civilistas de la arena política. Poco después del golpe que lo llevó al poder, las turbas leguiístas atacaron las oficinas de los diarios controlados por la oligarquía de Lima, La Prensa y El Comercio, y las casas de sus dueños. Durante el Oncenio, los oligarcas sospechosos de conspirar contra el régimen fueron encarcelados o deportados, entre ellos varios Aspíllaga, Miró Quesada y Prado, y miembros de otras familias mencionadas en 
el cuadro 1. Para los que se quedaron en Perú, el mensaje era claro. Como advirtió el hermano de Antero, Ramón Aspíllaga, en una carta de noviembre de 1919 a su sobrino: "Con respecto a la política [...] como si fuéramos extranjeros en nuestra propia tierra». ${ }^{17}$ No obstante, al mismo tiempo, el gobierno de Leguía protegió escrupulosamente los intereses económicos de los oligarcas y resistió a las fuerzas radicales emergentes que amenazaban su existencia privilegiada. Para muchos clanes oligárquicos, el Oncenio fue una era de prosperidad. Algunos vivían en un exilio europeo dorado, usualmente en París, respaldados por los ingresos de sus propiedades peruanas.

La Gran Depresión sacudió la economía dependiente de las exportaciones del Perú y socavó un régimen ya vulnerable. En agosto de 1930, Leguía fue derribado por un golpe militar encabezado por el teniente coronel Luis Sánchez Cerro. Su caída desató fuerzas políticas radicales, incluido el partido populista APRA, el Partido Comunista y las organizaciones laborales relacionadas que habían sido contenidas por el aparato represivo de Leguía. Los oligarcas se sintieron amenazados en múltiples frentes.

Perú se había convertido en una sociedad más moderna y compleja, con una economía más grande y diversificada, ciudades en crecimiento, clases trabajadoras y medias más grandes y, obviamente, niveles más altos de movilización política. ¿Podría la pequeña élite plutocrática imponerse a una sociedad así? Suponiendo que eso fuera posible, ¿era la oligarquía peruana lo suficientemente cohesionada para la tarea? Lo que se desarrolló en el Perú y duraría hasta el golpe militar de 1968, fue la República Cuestionada, un régimen en el que los oligarcas ya no gobernaban directa y abiertamente, sino que generalmente se manejaban, a menudo con la ayuda de oficiales del ejército aliados, para mantener al gobierno en manos amigas y superar las amenazas a sus intereses.

${ }^{17}$ Cartas administrativas, Lima-Cayaltí, noviembre 1919-noviembre 1920, Archivo General de la Nación [en adelante AGN], Archivo Agrario. 


\section{LA POLÍtica de los AÑos TREINTA}

La elección presidencial de 1931, celebrada un año después de la caída de Leguía, fue una confrontación tumultuosa entre dos figuras carismáticas: Sánchez Cerro, quien estaba respaldado por la mayor parte de la oligarquía, y el líder del APRA, Víctor Raúl Haya de la Torre. Ambos hombres cortejaron apoyo masivo con campañas nacionales a una escala sin precedentes en la historia peruana. Atrajeron a decenas de miles de peruanos a mítines de campaña. Esta era una nueva era política.

Haya tenía la organización política más fuerte. Sin embargo, Sánchez Cerro tenía algunas ventajas únicas. Era el hombre de acción que había derrocado a un dictador impopular. De un modesto origen provinciano, conocía el lenguaje de la calle y le encantaba bailar la marinera. Con rasgos mestizos oscuros, a muchos de los pobres de Perú les parecía "un cholo como nosotros», una frase que a menudo se repetía en ese momento. ${ }^{18}$ Pero a los pocos meses del golpe de 1930, el embajador estadounidense había informado a Washington: «Sánchez Cerro is about to be appropriated by the very reactionary old Civilista Party representing the landowning aristocracy and vested interests and headed by Antonio Miró Quesada, editor of El Comercio». ${ }^{19}$

Los instintos políticos de Sánchez Cerro fueron, como los oligarcas pronto lo percibieron, fundamentalmente conservadores. La oligarquía necesitaba a alguien que, como lo sugirió uno de los Aspíllaga en una carta, podría «tratar con fuete [...] a los apristas». ${ }^{20}$ Sánchez Cerro encajaba a la perfección. Al principio, lo festejaron, invitándolo a sus casas y al Club Nacional (donde sus rasgos oscuros deben de haber destacado). El coronel estaba aparentemente satisfecho con su atención y receptivo a sus ideas. Los oligarcas financiaron su campaña. ${ }^{21}$ Recibió un fuerte respaldo en el periódico de los Miró Quesada, El Comercio, el tradicional

18 Stein 1980: 82-128; Miró Quesada 1947: 34; Cartas particulares, Lima-Cayaltí, marzo 1930-febrero 1933, AGN, Archivo Agrario.

${ }^{19}$ Gerlach 1973: 276.

${ }^{20}$ Cartas particulares, Cayaltí-Lima, enero-diciembre 1931, AGN, Archivo Agrario.

${ }^{21} \mathrm{Ib}$. 
órgano civilista. ${ }^{22}$ Nunca más la oligarquía encontraría un candidato que pudieran respaldar, que combinara la política conservadora de Sánchez Cerro con su atractivo popular.

Sánchez Cerro obtuvo una convincente victoria del 51 al 35 por ciento sobre Haya de la Torre. Nombró un gabinete conservador que tranquilizó a la oligarquía. Como él explicó: «Yo solo gobierno con mis amigos». ${ }^{23}$ Los dieciséis meses de su presidencia estuvieron marcados por una confrontación social y política a menudo violenta. Los apristas atribuyeron su derrota al fraude electoral y Haya se consideraba el «Presidente Moral del Perú». ${ }^{24}$ Los miembros del partido se vieron envueltos en violentas confrontaciones públicas con sus oponentes y planearon el derrocamiento del gobierno de Sánchez Cerro. El conflicto laboral continuó en respuesta a las condiciones económicas y el trabajo de los organizadores apristas y comunistas. Sánchez Cerro respondió con severas medidas, que solo endurecieron la resistencia. En virtud de una nueva Ley de Emergencia, el gobierno hizo arrestar y deportar a la delegación del APRA en el Congreso de veintitrés miembros, suspendió la organización sindical y cerró publicaciones de la oposición. Después de una revuelta de los apristas en la ciudad norteña de Trujillo que fue aplastada en 1932, cientos de apristas de Trujillo fueron ejecutados de forma sumaria por los escuadrones de fusilamiento, en represalia por el asesinato de varias decenas de oficiales y hombres al retirarse los apristas. Este periodo alcanzó un desenlace aparentemente inevitable en 1933, con el asesinato de Sánchez Cerro a manos de un aprista de diecisiete ańos.

Con la aprobación de la legislatura (o lo que quedaba de ella), el general Óscar Benavides, un soldado que tenía una historia personal notable por lazos oligárquicos, fue nombrado para servir el resto del período presidencial de Sánchez Cerro. El general estaba relacionado

\footnotetext{
${ }^{22}$ Stein 1980:121.

${ }^{23}$ Basadre 1968, XIV: 18.

${ }^{24}$ Este punto de vista tiene poco apoyo entre los historiadores. Ver especialmente a Stein 1980: 188-197. También ver Pike 1967: 158 y Klarén 1976: 274. Este último señala que el historiador peruano, Jorge Basadre, consideraba que Haya era uno de los más honestos en la historia del país.
} 
con el clan Benavides de la lista del cuadro 1 y se había casado con una prima lejana de una rama más adinerada y socialmente destacada de la familia. En 1914, había colaborado con los hermanos Jorge y Manuel Prado, miembros de una prominente familia oligárquica, para derrocar al presidente Guillermo Billinghurst, un protopopulista cuyo gobierno de corta duración había amenazado los intereses de la élite. Durante los años de Leguía, que algunos miembros de ambas familias pasaron en el exilio, una de las hijas de Benavides se había casado con un Prado.

El gobierno de Benavides asumió una postura menos agresiva hacia el APRA, aunque el partido siguió siendo ilegal. Nombró a Jorge Prado como su primer ministro para dirigir un gabinete de "Paz y Concordia», pero Prado se vio obligado a renunciar bajo la presión de los sectores más conservadores y antiaprista de la élite. Como se había anticipado, Benavides organizó las elecciones en 1936, que marcaron el final del mandato de Sánchez Cerro.

\section{TRES FAMILIAS DE LA OLIGARQUíA Y LA POLÍTICA DE LOS AÑOS TREINTA}

La experiencia de tres familias con diferentes actitudes hacia el APRA ilumina la política de la élite de los años treinta.

\section{Los Aspíllaga}

Los Aspíllaga, dueños de la hacienda azucarera Cayaltí, fueron civilistas incondicionales en la República Aristocrática y antiapristas acérrimos en la República Cuestionada. Son significativos por ser representativos entre los hacendados de la costa, quienes conformaron el núcleo de la oligarquía —el sector más grande, mejor organizado y más activo políticamente-. Además, dejaron atrás un rico registro documental de sus actividades políticas y comerciales en correspondencia familiar. Los Aspíllaga, al igual que otros hacendados de la costa, se sintieron amenazados por el APRA por buenas razones: el partido tuvo muchos seguidores en la región y su retórica fue abiertamente antiplantaciones. Cuando no eran restringidos por los gobiernos de derecha en Lima, los organizadores sindicales apristas adoctrinaron a los trabajadores de las 
haciendas azucareras. Los Aspíllaga fueron de los primeros y más fuertes partidarios de Sánchez Cerro. En los meses previos a las elecciones de 1931, la correspondencia familiar describió al APRA como una «[amenaza contra] el orden constituido de todas las cosas» y argumentó que Sánchez Cerro merecía el apoyo de «nosotros, como todo el que tiene interés que conservar y proteger [...] [S] us principios y programa de gobierno son conservadores; lo propio son los que lo rodean más de cerca. No hay otro candidato con su popularidad». "[S]obre todo tiene el ejército que es esencial». ${ }^{25}$

La correspondencia de los Aspíllaga, complementada con otras fuentes y entrevistas, abre una ventana a la vida política de los grandes hacendados del azúcar y del algodón. Se destacan dos facetas: la intensa colaboración entre ellos, a veces trabajando con oligarcas no hacendados, y los diversos medios que utilizaban para alcanzar sus objetivos políticos. La correspondencia muestra que los Aspíllaga estuvieron en contacto regular con otros hacendados en Lima y en Lambayeque, donde se encontraba su plantación Cayaltí, por los problemas de control de los trabajadores. En repetidas ocasiones instaron a otros hacendados a resistir las demandas laborales y a negarse a reconocer los sindicatos. ${ }^{26}$ En un momento dado, se unieron a otros agricultores de Lambayeque en un pacto de aproyo mutuo para reembolsar a los miembros de los costos incurridos por resistir a las acciones laborales. ${ }^{27}$

Los hacendados costeños dependían de la cooperación de los funcionarios regionales para contener la actividad política y sindical que amenazaba sus intereses. Una carta etiquetada como «Privada», de Cayaltí a la oficina familiar en Lima, informaba sobre los gastos relacionados con el mantenimiento del «orden público y la tranquilidad de este departamento», incluido «una entrega hecha al Sub-Prefecto José M. Maldonado para contribuir a la prisión y deportación de ocho comunistas enviados

${ }^{25}$ Cartas particulares, Lima-Cayaltí, marzo 1930-febrero 1933; Cartas particulares, Cayaltí-Lima, enero-diciembre 1931, AGN, Archivo Agrario.

${ }^{26}$ Cartas particulares, Lima-Cayaltí, marzo 1930-febrero 1933; Cartas particulares, Cayaltí-Lima, enero-diciembre 1931, AGN, Archivo Agrario.

${ }^{27}$ Cartas reservadas, Lima-Cayaltí, enero 1946-diciembre 1948, AGN, Archivo Agrario. 
a Madre de Dios». ${ }^{28}$ Otra carta indica que los Aspíllaga planearon unirse a otros hacendados para comprar un automóvil para el prefecto, «con [quien] hay que estar siempre en la mejor armonía». ${ }^{29}$ Después de la revuelta de Trujillo, los Aspíllaga y otras dos familias ricas exportadoras estuvieron representadas en un comité para recaudar fondos para la compra de nuevos aviones y dotación de cuarteles para los militares, descritos en una carta de Lima como «una manifestación de simpatía al ejército y un efectivo paso por la defensa política y social de la Nación». ${ }^{30}$

La correspondencia de los Aspíllaga registra la activa participación de la familia en el manejo de la Sociedad Nacional Agraria. La SNA presionó con éxito al gobierno para que tomara medidas de alivio en la era de la depresión para la agricultura de exportación, desde tarifas de riego reducidas hasta la devaluación del sol peruano. ${ }^{31} \mathrm{El}$ control de la prensa fue una de las principales preocupaciones de los hacendados. En cartas a familiares, Ramón Aspíllaga Anderson se refiere a las campañas de la prensa "que manejamos desde la Sociedad Nacional Agraria» y señala que los hacendados controlaron «hasta dos periódicos, La Crónica y La Prensa». ${ }^{32}$ Los Aspillaga estaban en un grupo de hacendados que eran dueños de La Prensa, diario que era el principal defensor del candidato respaldado por la mayoría de los hacendados en 1936.

\section{Los Miró Quesada}

Los Miró Quesada, dueños de El Comercio, también habían sido parte de la dirección civilista. A diferencia de la mayor parte de la oligarquía, no tenían conexión con la economía de exportación ni con la banca. El diario era su único activo importante, pero los volvió ricos, socialmente prominentes y enormemente poderosos. La política de la familia, como se refleja en el periódico, se había desplazado hacia la derecha en los decenios de 1920

${ }^{28}$ Cartas particulares, Cayaltí,-Lima, enero-diciembre 1932, AGN, Archivo Agrario.

${ }^{29}$ Cartas reservadas, Lima-Cayaltí, mayo 1934-abril 1936, AGN, Archivo Agrario.

${ }^{30}$ Cartas particulares, Lima-Cayaltí, marzo 1930-febrero 1933, AGN, Archivo Agrario. ${ }^{31} \mathrm{Ib}$.

32 Cartas particulares, Lima-Cayaltí, marzo 1930-febrero 1933, AGN, Archivo Agrario. 
y 1930. Su reorientación surgió de una sensación de amenazas al orden social establecido, personificado por la Revolución Rusa y traído a casa por el aumento de los movimientos de izquierda en el Perú. En 1927, el periódico apoyó la campaña represiva de Leguía contra las organizaciones laborales y radicales. Varios días de artículos sobre el tema advirtieron sobre "los horrores del comunismo», «el terrorismo rojo», «el bolchevismo mundial» y aquellos que «envenenarían el corazón de la clase trabajadora contra quienes les dieron trabajo». ${ }^{33}$ Inicialmente, El Comercio aprobó a Hitler, sin oponerse a su trato con los judíos ni a la expansión agresiva de Alemania e interpretó el ascenso del nazismo como un golpe bienvenido contra el comunismo. ${ }^{34}$ En medio de la campaña electoral de 1936 en el Perú, la Guerra Civil española recibió una amplia cobertura en El Comercio, a veces de dos o más páginas completas, que simpatizaban con los fascistas.

Para los Miró Quesada, el APRA era una amenaza marxista más para la civilización cristiana, y Sánchez Cerro, a quien apoyaban ardientemente, era la respuesta. En 1931, ayudaron a formar su vehículo electoral, la Unión Revolucionaria, y respaldaron su campaña con su diario. ${ }^{35}$ Luis Miró Quesada ocupó un cargo en el gabinete inaugural de Sánchez Cerro. El Comercio bendijo las tácticas despiadadas de su gobierno contra el APRA.

La firme oposición de la familia al APRA se endureció aún más después del evento traumático conocido en la familia como «El crimen»: el 15 de mayo de 1935, Antonio Miró Quesada, el celoso antiaprista director de El Comercio, y su esposa, fueron asesinados frente al Club Nacional por un militante aprista de diecinueve años, quien afirmó haber actuado por su cuenta. Después del crimen, incluso los no apristas que mostraron algún grado de franqueza o indulgencia hacia el partido (como lo hizo un gran sector de la oligarquía en la década de 1960) se arriesgaron a incurrir en la ira de los Miró Quesadas y su periódico. Se volvieron contra Benavides después de que no ordenó la pena de muerte para el asesino de Antonio

${ }^{33}$ El Comercio, 9, 11 y 12 de junio de 1927

${ }^{34}$ Ver El Comercio, 11 y 12 de enero de 1932; 31 de enero de 1933; 10-16 de setiembre de 1935; 5-19 de noviembre de 1938; y Miró Quesada, 1953, I: 109 y II: 337.

${ }^{35}$ Masterson 2009: 123; Stein 1980: 121. 
Miró Quesada. Mientras el crimen unía a la familia contra el APRA, también produjo una crisis de sucesión entre los hermanos de Antonio. Aurelio, segundo a Antonio en orden de nacimiento, fue nombrado como director del periódico, a pesar de la objeción del cuarto hermano, Luis. Más tarde, el clan llegó a un compromiso que hizo que los dos hombres fueran codirectores, pero el decidido y políticamente astuto Luis sería la figura dominante en el periódico hasta su muerte en el año 1976.

\section{Los Prado}

Los Prado fueron otro clan civilista importante, con una fortuna diversificada en finanzas, industria y bienes raíces. Lo que se llamó el Imperio Prado giró en torno al Banco Popular, controlado por la familia, que floreció al aumentar la influencia política del clan en la década de 1930. La talentosa segunda generación de la familia, los Prado Ugarteche (nacidos entre 1870 y 1889) incluyó a Mariano, uno de los empresarios urbanos más exitosos de la República Aristocrática, un intelectual distinguido y político prominente. Pero su padre, el general Mariano Ignacio Prado, un héroe militar en algún momento, había dejado a sus descendientes un legado oscuro. Fue presidente de Perú en 1879 cuando el país, a pesar de su resistencia, tropezó con una guerra desastrosa con Chile. Tras varios meses de conflicto, Prado partió silenciosamente de Lima en un viaje a Estados Unidos y Europa con la intención declarada de negociar préstamos y compras de armas para su asediado país. Su sucesor emitió un decreto que acusó a Prado de desertar y lo despojó de su ciudadanía. Más tarde, se alegó que Prado se había fugado con los fondos designados para la compra de un buque naval muy necesario, aunque no había pruebas de que lo hubiera hecho.

Estos acontecimientos acosarían a sus descendientes. Cada vez que uno de los hijos del general era un candidato presidencial, un folleto titulado ¿Puede ser un Prado Presidente del Perú? circulaba en Lima. El texto, escrito de forma anónima, preguntaba si el hijo de un desertor y un ladrón estaba calificado para la presidencia. ${ }^{36}$ Un siglo después de

${ }^{36}$ El folleto circulaba durante las campańas electorales de 1936, 1939 y 1956. 
la guerra, uno de los bisnietos del general recordaría en una entrevista cómo un maestro de escuela preparatoria lo había acosado con continuos recordatorios de la leyenda negra que rodeaba a su famoso antepasado. Dado lo divulgado del cuento en Lima en aquella época, su experiencia debe haber replicado en la de muchos de los descendientes del general. Se creía ampliamente, tanto por miembros de la familia como por observadores cercanos, que los Prado Ugarteche aspiraban a la presidencia como una forma de reivindicar a su padre. De hecho, de 1915 a 1939, tres hermanos de Prado Ugarteche fueron sucesivamente, y por orden de nacimiento, presentados como candidatos presidenciales por la familia. ${ }^{37}$

Los Prado eran políticos astutos. Rápidamente, se dieron cuenta de los límites políticos y las oportunidades de la República Cuestionada posterior a 1930. La familia cultivó a figuras militares y líderes del APRA, incluso cuando el partido fue prohibido. Jorge, como se señaló anteriormente, dirigió el gabinete de «Paz y Conciliación» del general Benavides; como primer ministro visitó a Haya de la Torre en la cárcel y organizó su liberación. Los oficiales militares mal pagados sabían que los préstamos para la vivienda y los automóviles estaban disponibles para ellos en condiciones fáciles del Banco Popular de los Prado, que no insistiría en el reembolso. ${ }^{38}$ Jorge fue un candidato presidencial en la abortada elección de 1936, pero su hermano menor Manuel ganó la presidencia con la ayuda de Benavides y el apoyo parcial del APRA en 1939. Manuel sería elegido para su segunda presidencia en 1956, nuevamente con el respaldo del dictador militar en funciones y el apoyo abierto del APRA, dado a cambio de la promesa de Prado de legalizar el partido.

\section{La cohesión de la élite y la política de la República Cuestionada}

En su Burguesía e Industria en el Perú, 1933-1945, Baltazar Caravedo Molinari escribe sobre el surgimiento de un sector industrial dentro de la «clase dominante peruana». Según él, estos «industriales» fueron

\footnotetext{
${ }^{37}$ Información de entrevistas. Billinghurst 1915: 85; Chirinos Soto 1967: 70-1 y Portocarrero Suárez 1995: 21-38.

${ }^{38}$ Información de entrevistas.
} 
rechazados por los agroexportadores de la costa y los terratenientes de la sierra sobre temas que incluyen (a) tipos de cambio (b) políticas arancelarias y (c) financiamiento para la industria. Se esperaba que la Sociedad Nacional de Industrias (SNI) y organismos regionales similares defendieran a los industriales de la resistencia de la poderosa Sociedad Nacional Agraria y sus aliados políticos. Como Caravedo Molinari reconoce, la distinción entre estas dos facciones de clase no siempre fue clara. Los agroexportadores invirtieron en la fabricación e incluso sirvieron como funcionarios del SNI, en detrimento de aquellos cuyos intereses eran puramente industriales. Algunos de los industriales a los que se refiere eran productores provinciales menores, miembros poco probables de la «clase dominante peruana», un término que quedó indefinido. Caravedo Molinari retrata las elecciones de 1936 como una competencia entre los agroexportadores y los industriales. Demuestra que los agroexportadores eran fundamentales en la coalición que apoyaba la candidatura de Manuel Vicente Villarán y que algunos industriales importantes se encontraban entre los partidarios de Jorge Prado. La propia familia de Prado tenía importantes inversiones en la manufactura. Pero Caravedo Molinari no muestra que las elecciones se hayan librado por los problemas económicos que, según él, dividen a los industriales y a los agroexportadores. $\mathrm{El}$ asunto que más preocupó a los grupos contendientes y al gobierno de Benavides en 1936 fue el papel del APRA en el sistema político. ${ }^{39}$

Al igual que Caravedo Molinari, Geoffrey Bertram describe la política de este período en términos de una elite nacional fracturada. En su capítulo para la Cambridge History of Latin America, sostiene que la clave de la política nacional después de 1930 fue la tensión entre dos facciones de "la oligarquía»: (1) una facción exportadora de "derecha» que él identifica con los hacendados, su líder político Pedro Beltrán y los Miró Quesada, a quienes se opone (2) una facción «urbana-mercantil» que él identifica con los Prado. Sus referencias a "la oligarquía» y a las familias poderosas vinculadas al término, sugieren que su concepción de la élite nacional es más estrecha y exclusiva que la "clase dominante» 
de Caravedo Molinari. Rechaza la noción de una burguesía industrial emergente en la primera mitad del siglo veinte: «[O]ne or two industrialists [may have been] recruited into the oligarchy's ranks; but it does not appear that they formed any sort of separate group». ${ }^{40}$

Dos temas dividieron las facciones. El primero involucraba a la política monetaria y los tipos de cambio. Bertram encuentra que «Bankers and importers opposed devaluation [of the Peruvian $s o l$ ] and profited from exchange crises; exporters called for early devaluation when export markets fell». ${ }^{41}$ Cada una de las cinco crisis monetarias entre 1931 y 1967 se resolvió a favor de los exportadores. El tipo de cambio fue una cuestión recurrente y áspera, pero transitoria. El segundo tema, más contencioso, se refería al APRA y a las organizaciones sindicales apristas. Los oligarcas exportadores, dependientes de una fuerza laboral numerosa y de salarios bajos, apoyaron una línea dura represiva contra el APRA. Según Bertram, acomodar la mano de obra era más fácil para los oligarcas urbanos, porque estaban en una mejor posición para pasar sus costos laborales a los consumidores que los exportadores, que vendían su producto en mercados internacionales competitivos. Por esta razón, los oligarcas urbanos probablemente podrían estar más abiertos al compromiso con el APRA.

Había, sin duda, una amplia evidencia de conflicto político entre los oligarcas. Por ejemplo, dos figuras oligárquicas prominentes, Pedro Beltrán y Manuel Mujica Gallo, fueron responsables de la creación del panfleto burlón que ensayaba la leyenda negra de los Prado y su distribución durante la campaña de $1936 .{ }^{42}$ Otro ejemplo, mencionado anteriormente, fue el trato de los Miró Quesada por parte de sus compañeros cuando $E l$ Comercio comenzó a promover un programa de reforma nacional. Los Aspíllaga a menudo estaban en desacuerdo con los de la Piedra, dueńos de una plantación vecina, descritos en la correspondencia familiar como "grandes enemigos del apellido Aspíllaga». Los Aspíllaga

\footnotetext{
${ }^{40}$ Bertram 1991: 400.

${ }^{41}$ Ib.: 401.

${ }^{42}$ Miró Quesada Laos 1961: 480 y Portocarrero Suárez 1995: 31-2.
} 
creían que los de la Piedra estaban detrás de ataques políticos contra ellos. Las dos familias lucharon por los derechos de agua, que eran críticos para el cultivo de azúcar en la árida costa peruana. ${ }^{43}$

La elección presidencial de 1936, notable por los candidatos de élite que compiten entre sí, ha sido citada por Bertram y algunos otros académicos como evidencia de cohesión débil de la élite, prueba de que la oligarquía no podía gobernar porque sus miembros estaban divididos. ${ }^{44}$ Pero una mirada más cercana a la campaña de 1936 proporciona poco apoyo para esta interpretación. ${ }^{45}$

\section{Los candidatos}

Hubo cuatro candidatos presidenciales en la balota electoral de 1936:

Jorge Prado, que se presentó con el respaldo no disimulado del presidente Benavides. Prado fue el candidato del recién creado "Frente Nacional», una agrupación de partidos generalmente intrascendentes, algunos remanentes reducidos de partidos del siglo XIX, otros de orígenes más recientes. El apoyo oligárquico de Prado, fuera de su propia familia, fue mínimo.

Manuel Vicente Villarán, un abogado y académico conservador que había servido en gobiernos civilistas y que había sido presidente del Club Nacional. Si la oligarquía tenía un candidato, ese era Villarán.

Luis Flores, exministro del gabinete de Sánchez Cerro, quien se presentó como el heredero político de Sánchez Cerro y líder de su partido Unión Revolucionaria. Flores se presentó a sí mismo como un «fascista» y le dio a la UR una transformación fascista en un momento en que este tipo de partidos florecían en Europa. Sus seguidores de camisa negra proclamaron ideas fascistas, utilizaron el saludo fascista del brazo derecho

\footnotetext{
${ }^{43}$ Cartas reservadas, Cayaltí-Lima, julio-diciembre 1930, AGN, Archivo Agrario.

${ }^{44}$ Ver Klarén 1976: 279; Portocarrero Maisch 1982: 279 y Cotler 1978: 203-204 adoptan una postura similar.

${ }^{45}$ Mi lectura sobre las elecciones de 1936 se basa en Portocarrero Maisch 1982, Candela Jiménez 2010 y Guerra Martinière 1994; además de mis propias entrevistas realizadas en los setenta y otras fuentes citadas más adelante.
} 
levantado y atacaron a los apristas y a otros izquierdistas. ${ }^{46}$ No hubo apoyo oligárquico detectable para Flores.

Luis Eguiguren, un político moderado que se retiró del Frente Nacional y se presentó con el respaldo encubierto del APRA. Al igual que Flores, Eguiguren aparentemente no tenía apoyo oligárquico.

Todos los cuatro candidatos eran miembros de «la élite», aunque con diversos grados de elitismo. Villarán, Flores y Eguiguren fueron incluidos en el Libro de Oro de 1935, el registro social de las buenas familias limeñas. ${ }^{47}$ Solo Prado y Villarán eran miembros del más exclusivo Club Nacional, cuya membresía era de cientos en comparación con los varios miles de hogares que figuraban en el Libro de Oro. Finalmente, solo Prado era miembro de un clan oligárquico, notable por su riqueza, poder e inclusión en las ochenta y ocho familias en la cúspide de la sociedad limeña.

En los meses de maniobras políticas que precedieron a las elecciones de octubre de 1936, la pregunta crítica que enfrentaban el régimen y los candidatos era cómo, si acaso, el APRA participaría en el proceso. Como se esperaba, la comisión electoral de Benavides rechazó la candidatura de Haya de la Torre. Jorge Prado, quien había estado cortejando al APRA, al menos desde que estuvo en el gabinete de Benavides, pudo haber imaginado que se le permitiría postularse como candidato del Frente Nacional, con el respaldo discreto del APRA. Pero en 1936, Benavides, el padrino del Frente, quería excluir al APRA de cualquier forma. Esta situación creó un vacío para Eguiguren, que anunció su candidatura poco antes de las elecciones. ${ }^{4}$

\section{La oligarquía y las elecciones}

La aparición de Jorge Prado como candidato oficial en 1936 no es sorprendente. Los Prado, impulsados por su propia historia, habían aspirado durante mucho tiempo a la presidencia. Después de 1930,

${ }^{46}$ Lima, 7 de enero de 1938. National Archives. U.S. Department of State, U.S Embassy Peru. Record Group 84. Box 1, \#189.

${ }^{47}$ Prado, en ese momento embajador del Perú en Brasil, presuntamente no fue incluido, porque no radicaba en Lima y recién se había casado. Otros familiares de Prado fueron incluidos.

48 Sánchez 1968, II: 547-549 y Werlich 1978: 210. 
buscaron apoyo más allá de la élite entre los militares y el APRA. La relación de la familia con el general Benavides, descrita anteriormente, fue de larga data. Uno de los organizadores del Frente Nacional explicó sin rodeos el llamado político de Jorge a Eguiguren, quien obviamente albergaba sus propias ambiciones presidenciales: "Necesitamos un torero — me dijo- y ese torero es Jorge Prado, amigo del Presidente de la República y hombre rico». Prado, entendió Eguiguren, tuvo a su disposición los fondos del Banco Popular. ${ }^{49}$ Pero al retirarse del Frente, Eguiguren obtuvo el apoyo del APRA que Prado codiciaba.

En 1936, Jorge Prado solo tenía dos aliados oligárquicos identificables: el hacendado del azúcar Rafael Larco Herrera y el empresario Julio Ferrand, que se presentaron al Congreso con el programa de Jorge. Ambos hombres eran aparentemente pradistas. Larco se postuló para vicepresidente con el hermano de Jorge, Manuel, en 1939 y durante años estuvo asociado con el periódico de los Prado, La Crónica. Ferrand estuvo en el Congreso durante la presidencia de Manuel.

Los Miró Quesada eran sorprendentemente reticentes en 1936, un marcado contraste con el ańo 1931, cuando El Comercio le dio a Sánchez Cerro un respaldo total a plena voz. Los cognoscenti deben haber examinado minuciosamente las columnas del periódico en búsqueda de indicios de sus inclinaciones en las semanas previas a las elecciones del $11 \mathrm{de}$ octubre. Podrían haber llegado a la conclusión, a partir de la disparidad en la cobertura, que la Guerra Civil Española en curso era mucho más importante para los Miró Quesada que las elecciones peruanas. Alternativamente, podrían haber tomado el entusiasmo del diario por la «revolución» fascista de Franco como un guiño a favor de Flores. El Comercio publicó breves artículos sin compromiso sobre las actividades de la campaña de Flores, además de una nota bastante larga con foto de un gran mitin de Flores. ${ }^{50}$ Los atentos lectores también habrían notado que el diario dio una cobertura elaborada a un banquete pro-Villarán, reproduciendo en su totalidad los textos de los discursos que celebraban las virtudes del

\footnotetext{
${ }^{49}$ Eguiguren 1939: 84.

${ }^{50}$ El Comercio. 14 de setiembre de 1936.
} 
candidato. ${ }^{51}$ No se habrían sorprendido de que Eguiguren y Prado, dada su apertura al APRA, tuvieran poca cobertura, o que, el día antes de las elecciones, El Comercio informara sobre los discursos que sugerían que el gobierno de Benavides estaba discriminando a los opositores de Jorge. ${ }^{52}$

El enfoque no comprometido del periódico para estas elecciones reflejó la división personal e ideológica dentro de la familia. ${ }^{53}$ La cuestión de la dirección de El Comercio, después del asesinato de Antonio el año anterior, continuaba sin resolverse. Ideológicamente, la familia probablemente se dividió entre partidarios de Villarán y de Flores. Carlos Miró Quesada Laos, hijo de Antonio y un talentoso periodista, fue uno de los primeros campeones peruanos del fascismo europeo. ${ }^{54}$ Otros miembros de la familia se resistieron a la publicación de sus artículos profascistas más extremos. Carlos fue un probable partidario de la candidatura fascista de Flores. En los últimos años, su tío Luis y los aliados de este último lo sacaron del periódico. ${ }^{55}$

En 1936, los Prado y los Miró Quesada fueron impulsados por preocupaciones idiosincráticas arraigadas en tragedias familiares: la leyenda negra del general y el asesinato de Antonio. En contraste, los Aspíllaga, que apoyaron a Villarán, actuaron a partir de intereses de clase bien definidos que compartieron con gran parte de la oligarquía. Villarán fue un antiguo civilista y conservador antiaprista a quien los Aspíllaga y sus compañeros conocían y confiaban. Gustavo Aspíllaga, en una carta a un amigo inglés escrita varios meses antes de la elección, describió a Villarán como «a great man who we are helping in every way [...] Villarán has with him all the productive forces of the country; that ought to be enough to get him elected, but one sees some queer things in politics nowadays». ${ }^{56}$

La candidatura de Villarán fue organizada por Pedro Beltrán, el líder político de los hacendados costeños. Fue apoyado por La Prensa, el

${ }^{51}$ El Comercio. 4 de setiembre de 1936.

${ }^{52}$ El Comercio. 10 de octubre de 1936.

${ }^{53}$ Entrevistas con miembros de la familia y Pardo Castro 1961: 20-1.

${ }^{54}$ Lima, 28 de junio de 1938. National Archives. U.S. Department of State, U.S Embassy Peru. Record Group 84. Box 1, \#189 Lima, 7 de enero de1938) y \#488; Miró Quesada Laos 1940.

55 Pardo Castro 1961: 31

${ }^{56}$ Cartas de Gustavo Aspíllaga, 1932, AGN, Archivo Agrario. 
defensor de los intereses de los exportadores, que era propiedad de un grupo de hacendados. La participación de Beltrán y La Prensa sugiere el apoyo menos visible de familias como los Gildemeister, los mayores terratenientes del país, que preferían mantener un perfil político bajo. ${ }^{57}$ El amplio apoyo oligárquico de Villarán es evidente en la lista de familias representadas en el banquete pro-Villarán reportado en El Comercio. Entre los celebrantes se encontraban miembros de las siguientes familias, a menudo dos o más de cada uno: Aspíllaga, Beltrán, Lavalle, Ayulo, Pardo, Olaechea, Berckemeyer, Málaga, Bentín, Barreda, Orbegoso y Carrillo. Un anuncio de la campańa en El Comercio nombra a los miembros de las familias Mujica, Lavalle y Olaechea como candidatos a las curules del Congreso de Lima en el programa de Villarán. ${ }^{58}$ La lista combinada de clanes oligárquicos identificados públicamente con la candidatura de Villarán es notable por su diversidad. Se incluyen familias de hacendados, mineros, comerciantes y banqueros (consulte el cuadro 1 más arriba para conocer los intereses económicos de las familias).

\section{Lo que nos dicen las elecciones de 1936}

Villarán, el candidato de la oligarquía, llegó en último lugar, según el total de votos en el momento en que el conteo fue cortado por el régimen (Tabla 1). Eguiguren obtuvo un fuerte primer lugar, pero Benavides no estaba dispuesto a aceptar la victoria de una persona que era el candidato no oficial del APRA. Es notable que los dos candidatos que tenían algún reclamo sobre un público popular, Eguiguren y el fascista Flores, obtuvieron la mayoría de los votos. El total de Eguiguren superó el voto combinado de Villarán y Prado, los dos candidatos con algún apoyo oligárquico conocido. Lo que aprendemos es lo siguiente: Si los oligarcas ya no podían ganar las elecciones, no era porque estuvieran divididos (la mayoría se había alineado detrás de Villarán), sino porque carecían de apoyo popular en la era de la política de masas posterior a la de Leguía.

${ }^{57}$ Guerra Martinière 1994: 167. Sobre los Gildemeisters y Beltrán, ver Gilbert 2017: 130, 256-7.

${ }^{58}$ El Comercio. 2 de octubre de 1936 


\section{Tabla 1. Voto presidencial de 1936}

\begin{tabular}{lll}
\hline Eguiguren & 37.1 & \\
Flores & 29.1 & \\
Prado & 20.7 & \\
Villarán & 13.1 & \\
\hline TOTAL & $100.0 \quad(\mathrm{n}=70,040)$ \\
\hline
\end{tabular}

Fuente: Portocarrero 1982: 70 y La Prensa, 17 de octubre de 1936.

El amplio apoyo oligárquico para Villarán en 1936 contradice la concepción, compartida por Bertram y otros, sobre las facciones opuestas de los exportadores-rurales y urbanas-domésticas de la élite. El mismo Bertram reconoce que la supuesta línea entre los dos a veces era borrosa. Como se señaló anteriormente, muchos clanes tenían intereses que atravesaban los sectores, y las fortunas de los banqueros, comerciantes y directores de periódicos no eran independientes de la salud de la economía exportadora. En cualquier caso, la gran mayoría de los oligarcas eran exportadores. Entre las 29 familias enumeradas en el cuadro 1, 20 eran familias exportadoras, incluidas 15 de hacendados. El núcleo hacendado de la oligarquía era, como revela la vida política de los Aspíllaga, bien organizado, activo y cohesionado. El otro grupo exportador significativo, los mineros, mantuvo un perfil más bajo, siguiendo el liderazgo de los hacendados en la política.

Las fortunas de las nueve familias no exportadoras se concentraban principalmente en la banca o el comercio. La mayoría compartió opiniones orientadas a la importación en cuestiones monetarias. Algunos, como sugiere Bertram, estaban más abiertos al APRA que a sus pares exportadores. Pero nunca formaron una facción unida, cooperando en la defensa de intereses mutuos. El Comercio de los Miró Quesada defendió consistentemente las opiniones monetarias de los importadores; al fin y al cabo, eran productores nacionales, dependientes de maquinaria e insumos importados. Pero nunca estuvieron abiertos al APRA.

A medida que se acercaban las elecciones presidenciales de 1956, los miembros de dos prominentes familias bancarias, Manuel Prado y Hernando de Lavalle, compitieron por el apoyo del APRA. Prado ganó, habiendo obtenido la cooperación del titular, el presidente general 
Manuel Odría (como siempre, los Prados dependía del APRA y del ejército). La victoria trajo ventajas significativas para el banco de Prado. Si había un sector urbano-importador de la oligarquía, no era muy cohesivo.

La noción de una oligarquía fracturada se debe en gran medida a la importancia de dos familias atípicas: Prado y Miró Quesada. Como la mayoría de la oligarquía, estas familias habían sido parte de la élite civilista y eran miembros prominentes de la sociedad de Lima. Pero solo una familia oligárquica ganaría la presidencia durante la República Cuestionada, y solo una controlaría el diario más importante del país, que dio forma a la agenda nacional durante décadas. Ambas fueron impulsadas por preocupaciones idiosincráticas, de hecho, tragedias familiares, en lugar de intereses de clase o incluso intereses sectoriales. Los Prado querían la reivindicación histórica para su fundador. Los Miró Quesada, a comienzos de la década de 1930, posiblemente fueron motivados por preocupaciones de clase en su vociferante oposición al APRA. Pero, después de 1935, fueron estimulados menos por intereses de clase o sectoriales que por la memoria de «El Crimen». A fines de los años cincuenta y sesenta, cuando la oligarquía se movió hacia un modus vivendi con el APRA, los Miró Quesada se mantuvieron en contra de los apristas. Durante estos años, El Comercio hizo un llamado a la reforma social y a la modernización de la economía doméstica. Pero no hay evidencia de colaboración entre la familia y los empresarios urbanos, oligárquicos o no, que su programa asumió. Ampliamente respetados, no se identificaron con ninguna facción y no tenían aliados políticos. ${ }^{59}$

Los oligarcas peruanos a veces estaban divididos, pero nunca en facciones duraderas y coherentes. Estaban unidos por sus vínculos sociales y sus intereses económicos compartidos. Durante la mayor parte de un siglo, su centro de gravedad político fue la mayoría exportadora, guiado por su núcleo agrícola.

${ }^{59}$ A fines de la década de 1940, los Miró Quesada enfrentaban fuerte competencia comercial e ideológica, después de que Pedro Beltrán asumió control personal de $L a$ Prensa. Defensor de intereses exportadores, La Prensa era un periódico más moderno y atractivo para los lectores. No obstante, La Prensa nunca superó el prestigio de El Comercio, el periódico más viejo del país (fundado 1839) y su reputación de independencia editorial (Gilbert 2017: 221-32). 


\section{CONCLUSIONES}

Los desafíos críticos para la teoría de la élite son los mismos que para cualquier élite gobernante: la debilidad de la cohesión de la élite y el surgimiento de la oposición de masas organizada. Los teóricos de la élite clásica reconocieron el ascenso y la caída de las minorías gobernantes. Vilfredo Pareto es recordado por su observación: «La historia es el cementerio de las aristocracias». ${ }^{60}$ Tanto él como Gaetano Mosca creían que dicha afirmación carecía de importancia, pues una vieja elite será reemplazada por una nueva. Una minoría siempre gobierna. Esto es cierto solo en un sentido trivial. Los que tienen el poder formal son inevitablemente pocos, pero en la medida en que son acosados por poblaciones organizadas, por élites en competencia, por reglas e instituciones limitantes, la noción de una élite gobernante se vuelve problemática.

En el caso peruano, el poder oligárquico fue inicialmente socavado por la división entre la élite civilista. Después de Leguía, los oligarcas se unieron frente a la resistencia popular organizada. Las elecciones de 1936 demostraron que la cohesión de la élite, aunque fuerte, no podía garantizar la victoria frente a la movilización popular. Pero si no podían gobernar directamente, los oligarcas aprendieron que podían someter al gobierno a sus propósitos. Y cuando una administración llegó al poder en 1945 que estaba más allá de su control y amenazaba directamente sus intereses, orquestaron su eliminación. Entre los que organizaron y financiaron el golpe militar de 1948 que derrocó al presidente José Luis Bustamante, se encontraban algunos nombres familiares: Aspíllaga, Beltrán, Prado, Miró Quesada, Pardo y Gildemeister. ${ }^{61}$ En la década de los sesenta, la mayoría de la oligarquía, aliada con un APRA domesticada, frustró el programa reformista de Fernando Belaúnde Terry. Los oligarcas ya no gobernaban el Perú, pero el poder oligárquico perduraría más allá de toda expectativa razonable hasta que fuera extinguido por la revolución de 1968 del general Velasco.

\footnotetext{
${ }^{60}$ Pareto 1935: 1430.

${ }^{61}$ Gilbert 2017: 128-30.
} 


\section{BIBLIOGRAFÍA}

Baltzell, E. Digby. 1958. Philadelphia Gentleman: The Making of a National Upper Class. Glencoe: The Free Press.

Basadre, Jorge. 1968. Historia de la República del Perú. Lima: Editorial Universitaria. 16 volúmenes.

. 1971. Introducción a las bases documentales para la historia de la República del Perú, con algunas reflexiones. Lima: Ediciones P.L. Villanueva. 2 volúmenes. Belmont Parker, William. 1919. Peruvians of To-Day. Lima: [s.n].

Bertram, Geoffrey. 1974a. Development Problems in an Export Economy: A Study of Domestic Capitalists, Foreign Firms, and Government in Perú: 1919-1930. Tesis de doctorado en Historia. Oxford: Oxford University.

. 1974b. «Metal Mining in Perú Since the Depression». Artículo no publicado. . 1991. «Peru, 1930-1960». En Bethell, Leslie (ed.). The Cambridge History of Latin America. Volumen VIII. Cambridge: Cambridge University Pres.

Billinghurst, Guillermo. 1915. El Presidente Billinghurst a la Nación. Santiago: Imprenta Diener.

Bollinger, William. 1971. The Rise of United States Influence in the Peruvian Economy. Tesis de magíster en Historia. Los Angeles: University of California. Bottomore, Tom. 1966. Elites in Modern Society. New York. Pantheon Book.

Bourricaud, Francois. 1969a. "Notas acerca de la oligarquía peruana». En Matos Mar, José (coord.). La oligarquía en el Perú. Tres ensayos y una polémica. Traducción de Rosalía Avalos. Lima: Instituto de Estudios Peruanos, 13-54.

. 1969b. «La clase dirigente peruana: oligarcas e industrales». En Matos Mar, José (coord.). La oligarquía en el Perú. Tres ensayos y una polémica. Traducción de Rosalía Avalos. Lima: Instituto de Estudios Peruanos, 149-166.

1970. Power and Society in Contemporary Perú. New York. Praeger Publishers.

Burga, Manuel y Alberto Flores Galindo. 1984. Apogeo y crisis de la República Aristocrática. Lima: Ediciones Rikchay Perú.

Candela Jiménez, Emilio. 2010. «Polarización e ideologización en un escenario político: etapas y desarrollo de la campaña electoral de 1936». Histórica. Número 34: 129-175.

Capuñay, Manuel A. 1951. Leguía, vida y obra del constructor del gran Perú. Lima: Compañía de Impresiones y Publicidad Enrique Bustamante y Ballivian.

Caravedo Molinari, Baltazar. 1976. Burguesía e industria en el Perú, 1933-1945. Lima. Instituto de Estudios Peruanos.

Chirinos Soto, Enrique. 1967. Actores en el drama del Perú y del mundo. Segunda edición. Lima: [s.n.].

Cotler, Julio. 1978. Clase, Estado y Nación en el Perú. Lima: Instituto de Estudios Peruanos. 
Domhoff, G. William. 1974. The Bohemian Grove and Other Retreats: A Study in Ruling Class Cohesiveness. New York: Harper and Row.

Eguiguren, Luis. 1939. El usurpador (para la historia). Lima: Talleres Gráficos "Ahora».

Favre, Henri. 1969. «El desarrollo y las formas de poder oligárquico en el Perú». En Matos Mar, José (coord.). La oligarquía en el Perú. Tres ensayos y una polémica. Traducción de Rosalía Avalos. Lima: Instituto de Estudios Peruanos, 90-147.

Gerlach, Allen. 1973. Civil-Military Relations in Peru: 1914-1945. Tesis de doctorado en Historia. Albuquerque: University of New Mexico.

Gilbert, Dennis. 2017. The Oligarchy and the Old Regime in Latin America, 1880 to 1970. New York: Rowman \& Littlefield.

Gonzales, Michael J. 1985. Plantation Agriculture and Social Control in Northern Peru, 1875-1933. Austin: University of Texas Press

Guerra Martiniere, Margarita. 1994. «La República, 1900-1948». Historia General del Perú. Octavo tomo. Lima: Editorial Brasa.

Huertas Vallejos, Lorenzo. 1974. Capital burocrático y lucha de clases en el sector agrario (Lambayeque, Perú 1920-50). Lima: Seminario de Historia Rural Andina.

Klaren, Peter. 1976. La formación de las haciendas azucareras y los origenes del Apra. Lima: Instituto de Estudios Peruanos.

. 2000. Peru: Society and Nationhood in the Andes. New York: Oxford University.

Lasarte, Ferreyros, Luis. 1938. Familias establecidas en el Perú durante la Conquista y el Virreynato. Lima: Imprenta Torres Aguirre.

. 1993. Apuntes sobre cien Familias establecidas en el Perú. Lima: Rider Ediciones Nacionales.

Malpica, Carlos. 1973. Los dueños del Perú. Lima: Ediciones Peisa.

Masterson, Daniel. 2009. History of Peru. Greenwood CT: Westwood Press.

Matos Mar, José (coord.) 1969. La oligarquía en el Perú. Buenos Aires: Amorrortu Editores.

Mendiburu, Manuel de. 1874-1890. Diccionario histórico biográfico. Lima: Imprenta Bolognesi, 8 volúmenes.

Miller, Rory. 1982. «The Coastal Elite and Peruvian Politics, 1895-1919». Journal of Latin American Studies. Número 14: 97-120. https://doi.org/10.1017/ S0022216X0000359X

Miró Quesada, Luis. 1940. Lo que he visto en Europa. Lima: [s.n.]. . 1947. Sánchez Cerro y su tiempo. Buenos Aires: El Ateneo. . 1953. Ofrenda Jubilar del Personal de El Comercio. Lima: El Comercio.

Miró Quesada Laos, Carlos. 1961. Autopsia de los partidos políticos. Lima: Ed. Páginas Peruanas.

Moreno Mendiguren, Alfredo. 1956. Repertorio de noticias breves sobre personajes peruanos. Madrid: Sánchez Ocana. 
Mosca, Gaetano. 1939. The Ruling Class. New York \& London: McGraw Hill Book Company, 1939.

Pacheco, Artemio. 1923. Cabezas dirigentes del alto comercio del Perú. Lima: Cámara de Comercio.

Pardo Castro, José. 1961. Amos y siervos en El Comercio. Lima: Periodistas Unidas. Pareto, Vilfredo. 1935. The Mind and Society. New York: Harcourt Brace.

Paz Soldán, Juan. 1921. Diccionario de peruanos contemporáneos. Lima: Imprenta Gil. Pike, Frederick. 1967. A Modern History of Perú. New York: Praeger.

Portocarrero Maisch, Gonzalo. 1982. «La oligarquía frente a la reivindicación democrática (las opciones de la derecha en las elecciones de 1936)». Apuntes. Número 7: 61-73 https://doi.org/10.21678/apuntes.12.180

Portocarrero Suárez, Felipe. 1995. El Imperio Prado: 1890-1970. Lima: Universidad del Pacifico, Centro de Investigación.

.2013. Grandes fortunas en el Perú: 1916-1960. Riqueza y filantropía en la élite económicas. Lima: Universidad del Pacífico.

Quiroz, Alfonso W. 1984. "Financial Leadership and the Formation of Peruvian Elite Groups, 1884-1930». Journal of Latin American Studies. Número 20: 49-81. https://doi.org/10.1017/S0022216X00002480

Sánchez, Luis Alberto. 1969. Testimonio personal: memorias de un peruano del siglo $X X$. Lima: Editorial Villasán, 4 volúmenes.

Stein, Steve. 1980. Populism in Peru: The Emergence of the Masses and the Politics of Social Control. Madison: University of Wisconsin Press.

Thorndike, Guillermo. 1973. El Caso Banchero. Barcelona: Barrel Edifice.

Thorp, Rosemary y Geoffrey Bertram. 1978. Peru 1890-1977: Growth and Policy in an Open Economy. New York: Columbia University Press. https://doi. org/10.1007/978-1-349-03870-1

Werlich, David. 1978. Peru: A short history. Carbondale: Southern Illinois University Press.

Fecha de recepción: 21/IX/2018

Fecha de aceptación: 5/I/2019 